\title{
Knowledge and Awareness on Various Suturing Techniques Used in Minor Oral Surgeries Among Dental Students
}

\author{
B.Aishwarya Reddy ${ }^{1}$ and Pradeep $D^{2}$ \\ ${ }^{1}$ Saveetha Dental College and Hospitals, Saveetha Institute of Medical and \\ Technical Sciences,Saveetha University, Chennai 600077. Tamil Nadu, India \\ ${ }^{2}$ Associate Professor, Department of Oral and Maxillofacial surgery, Saveetha Dental \\ College and Hospitals, Saveetha Institute of Medical and Technical Sciences, Saveetha \\ University, Chennai 600077, Tamil Nadu, India
}

\section{ABSTRACT}

There are oral surgical procedures that are part of the broad scope of general dentistry. These include routine oral surgery such as the extraction of teeth, suturing wounds, and biopsying suspicious soft tissue lesions. The ability to suture is one of the essential skills required of anyone planning to perform surgery.Learning to suture in an expert manner requires an understanding of the proper techniques and dedicated practice. The aim of the study is to evaluate the knowledge and awareness on various suturing techniques used in minor oral surgeries among dental students. An online questionnaire was prepared and circulated among the students of dental colleges.The sample size is 100. The data was tabulated and then imported to SPSS software by IBM and the statistical chi square test was done. $91 \%$ of the students were aware of the various suturing techniques practiced in dentistry. $47 \%$ of the students use simple continuous suturing technique in their practice. When the correlation was done between best suture material and best time for suture removal, $\mathrm{P}$ value was 0.000 which was statistically significant. Within the limits of the study, dental students were aware of various suturing techniques used in minor oral surgeries.

KEY WORDS: DENTAL STUDENTS, SUTURE MATERIAL, ORAL SURGERIES, SUTURING TECHNIQUE.

\section{INTRODUCTION}

Successful dental suturing in oral surgery is dependent on accurate coaptation of the flaps. Various methods and materials like sutures, stents, paste dressings, tissue tacks and adhesives have been used for precise flap placement. Suturing has remained the most popular method (Andrade, Weissman and Reis, 2006). The term

\section{ARTICLE INFORMATION}

*Corresponding Author: pradeep@saveetha.com

Received 10th June 2020 Accepted after revision 9th August 2020

Print ISSN: 0974-6455 Online ISSN: 2321-4007 CODEN: BBRCBA

Thomson Reuters ISI Web of Science Clarivate Analytics USA and Crossref Indexed Journal

\section{Clarivate}

NAAS Journal Score 2020 (4.31) SJIF: 2020 (7.728)

A Society of Science and Nature Publication,

Bhopal India 2020. All rights reserved.

Online Contents Available at: http//www.bbrc.in/

Doi: http://dx.doi.org/10.21786/bbrc/13.7/19 "suture" describes any strand of material utilized to ligate blood vessels or approximate tissues. The technique of closing wounds by means of needle and thread is several thousand years old ('Atlas of cosmetic and reconstructive periodontal surgery', 1995). The history of surgical sutures can be traced back to ancient Egypt, and the literature of the classical period contains a number of descriptions of surgical techniques involving sutures (Marsh, 2001). Before catgut became the standard surgical suture material towards the end of the 19th century, many different paths had been followed to find a suitable material for sutures and ligatures (Gomez, 2007). Materials that had been tried included gold, silver and steel wire, silk, linen, hemp, flax, tree bark, animal and human hair, bow- strings, and gut strings from sheep and goats. At the beginning of the 19th century metal threads were tested as suture material(Wilson, 2006; Gomez, 2007). 
At that time inertness of a material with respect to body tissues was considered an advantage. Nevertheless, metal threads had major disadvantages: their stiffness rendered knot- tying more difficult and could easily result in knot breakage; in addition, suppuration of the wound edges occurred frequently (Howe and Zamet, 1971). These negative experiences with metal contributed to the establishment of silk as the number one suture material(Kim et al., 2011). Wounds sewn with silk cicatrized within a few days, and the small knot caused no problems. For these reasons most surgeons at that time chose silk for sutures and vessel ligatures(Siervo, 2008).

A variety of suture materials and suture/needle combinations are available. The choice of suture for a particular procedure is based on the known physical and biologic characteristics of the suture material and the healing properties of the sutured tissues(Dragovic et al., 2020). The selection of suture material is based on: The condition of the wound, the tissues to be repaired, the tensile strength of the suture material, knot-holding characteristics of the suture material, and the reaction of surrounding tissues to the suture materials(Postlethwait, Willigan and Ulin, 1975).

Suturing is an important aspect of any dental or surgical procedure where there is either cutting or injury to the soft tissue in the oral cavity(Taylor and Bayat, 2003). Proper placement of sutures can help in faster and proper healing of the tissues involved(Trimbos, Van Rijssel and Klopper, 1986). It helps in primary healing of the wound site and also prevents any secondary infections. It is very important to note that the selection of the correct type of suture needle in dentistry is as important as the suturing technique as it helps in properly piercing and also maintaining the integrity of the tissue(Malik, 2016).

With a rich case bank established over 3 decades we have been able to publish extensively in our domain (Abdul Wahab et al., 2017; Eapen, Baig and Avinash, 2017; Patil et al., 2017; Jain and Nazar, 2018; J et al., 2018; Marimuthu et al., 2018; Wahab et al., 2018; Abhinav et al., 2019; Ramadorai, Ravi and Narayanan, 2019; Senthil Kumar et al., 2019; Sweta, Abhinav and Ramesh, 2019). Based on this inspiration we aim to estimate the knowledge and awareness on various suturing techniques used in minor oral surgeries among dental students.

\section{MATERIAL AND METHODS}

An online questionnaire was prepared and circulated among the adolescent population. This questionnaire was prepared using a survey planet. The questionnaire consists of 12 questions. The sample size for the study was 100 . It was an online setting where two reviewers are involved in this study for the validity checking of the questionnaire.The data was collected, verified, tabulated and analysed. All statistical analysis was done using SPSS by IBM.The statistical Chi square test was done, where if the $p$ value is found out to be less 0.05 , it is statistically significant. The data was imported to SPSS and the descriptive statistics with frequency analysis was done. The obtained data were represented graphically as bar charts. The dependent variables considered for the study are dental students, suturing, minor oral surgeries and the independent variables are the cause of the treatment and age of the patient.

\section{RESULTS AND DISCUSSION}

A total of 100 dental students participated in this survey. When asked if the students were aware of various suturing techniques practiced in dentistry, 91\% of the students were aware and 9\% of the students were not aware of various suturing techniques practiced in dentistry (Figure 1).

Figure 1: Bar chart showing responses to the question, "Are you aware of the various suturing techniques practiced in dentistry?". X axis represents the awareness on various suturing techniques practised in dentistry and $\mathrm{Y}$ axis represents the number of dental students participated in the survey.Majority of respondents reported "aware"(91\%). Blue indicates "aware" and green indicates " not aware"

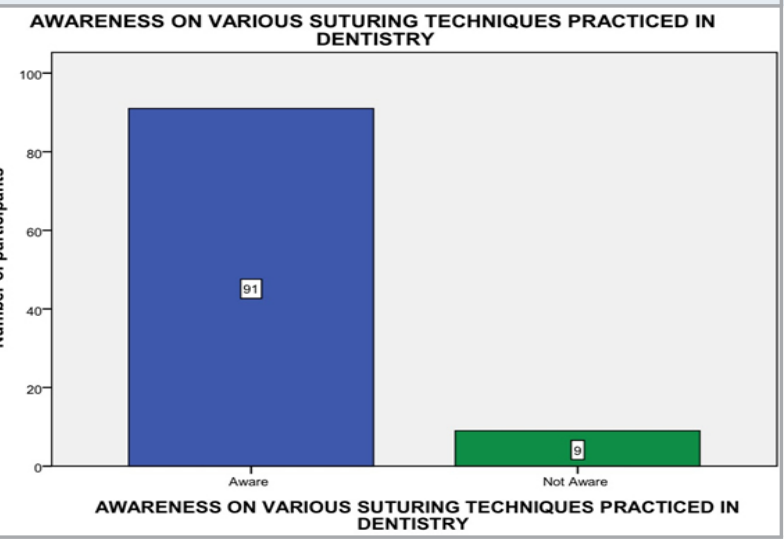

Figure 2: Bar chart showing responses to the question, “ Which suturing technique do you use?”. X axis represents the suturing technique used by the dental students and $\mathrm{Y}$ axis represents the number of dental students participated in the survey.Majority of respondents reported "simple continuous suturing technique" $(47 \% \%)$. Blue indicates "Interrupted", green indicates " simple continuous", white indicates "vertical mattress", violet indicates "horizontal mattress" and red indicates "criss cross"

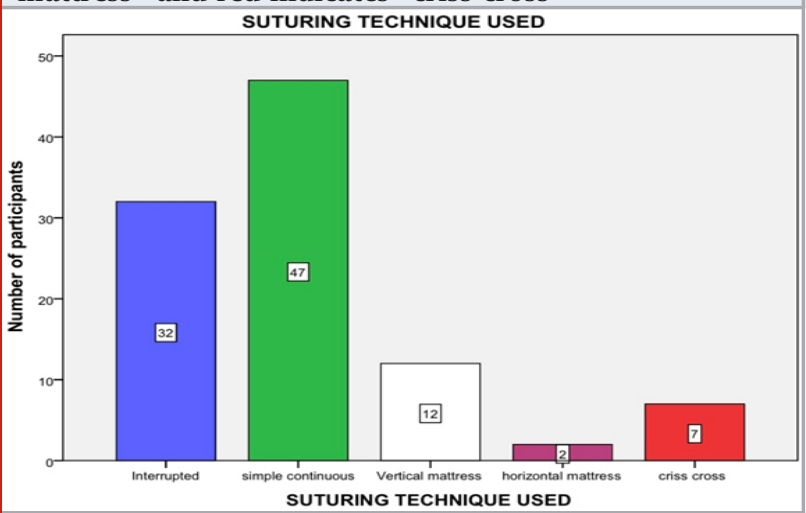


A study given by Koshak HH, 2017(Koshak, 2017), states that knowledge of the suture, needles (type, size, shape), instruments, and techniques are absolutely necessary in order to be a competent surgeon. There is no suture superior to the others in each aspect. The differences in terms of tissue reaction and bacterial adhesion between sutures should be always considered in the selection of the appropriate suturing material.

Figure 3: Bar chart showing responses to the question, "Which one of the following suturing techniques, do you think is the best?". $\mathrm{X}$ axis represents the best suturing technique in the opinion of dental students and $\mathrm{Y}$ axis represents the number of dental students participated in the survey. Majority of respondents reported "Interrupted suturing technique" (75\%). Blue indicates "Interrupted" , green indicates "simple continuous", white indicates "vertical mattress", violet indicates "horizontal mattress" and red indicates "criss cross"

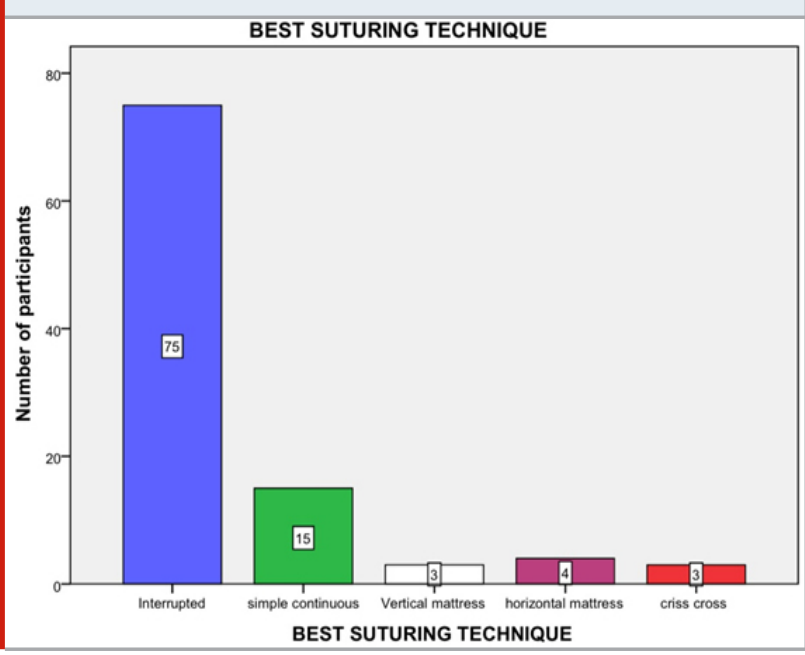

The students were asked about the suturing technique they prefer, where $47 \%$ of the students prefer simple continuous suturing technique, followed by interrupted suturing technique with 32\%, vertical mattress suturing technique with $12 \%$, criss cross suturing technique with $7 \%$ and horizontal mattress technique with $2 \%$ (Figure 2). A study given by Terrence J Griffin, et. al, 2011 (Griffin, Hur and Bu, 2011), shows that simple interrupted sutures were used in the majority for each surgical procedure.This study is not consensus to the present study, because of the multiple trends and limited sample size. Simple continuous suturing technique has advantages such as more water tight closure, distributes the tension uniformly, rapid technique and only two knots with associated tags are needed.

The students were also asked about the best suturing technique, where $75 \%$ responded as interrupted suturing technique, $15 \%$ as simple continuous suturing technique, $4 \%$ as horizontal mattress technique and $3 \%$ as vertical mattress and criss cross suturing technique each (Figure 3). A study given by Eliason JA, et.al, 1990 (Eliason and McCulley, 1990), says that interrupted sutures are easy to place, have greater tensile strength, and have less potential for causing wound edema and impaired cutaneous circulation. Interrupted sutures also allow the surgeon to make adjustments as needed to properly align wound edges as the wound is sutured.

Figure 4: Bar chart showing responses to the question, "Which one of the following do you think is the best suture material?". X axis represents the best suture material in the opinion of dental students and $\mathrm{Y}$ axis represents the number of dental students participated in the survey. Majority of respondents reported "Natural"(32\%). Blue indicates "Natural" , green indicates "Synthetic", violet indicates "Monofilament" and yellow indicates "Multifilament"

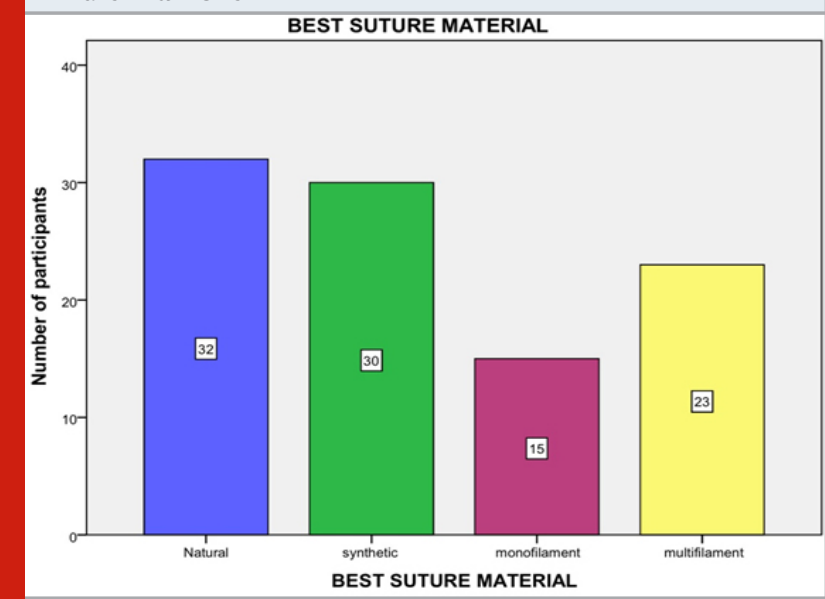

Figure 5: Bar chart showing responses to the question, "Which one of the following do you think is the best time for suture removal?". X axis represents the best time for suture removal in the opinion of dental students and $\mathrm{Y}$ axis represents the number of dental students participated in the survey.Majority of respondents reported " 10 days" $(44 \%)$. Blue indicates " 1 week" , green indicates " 10 days", violet indicates " 2 weeks" and yellow indicates "more than 2 weeks"

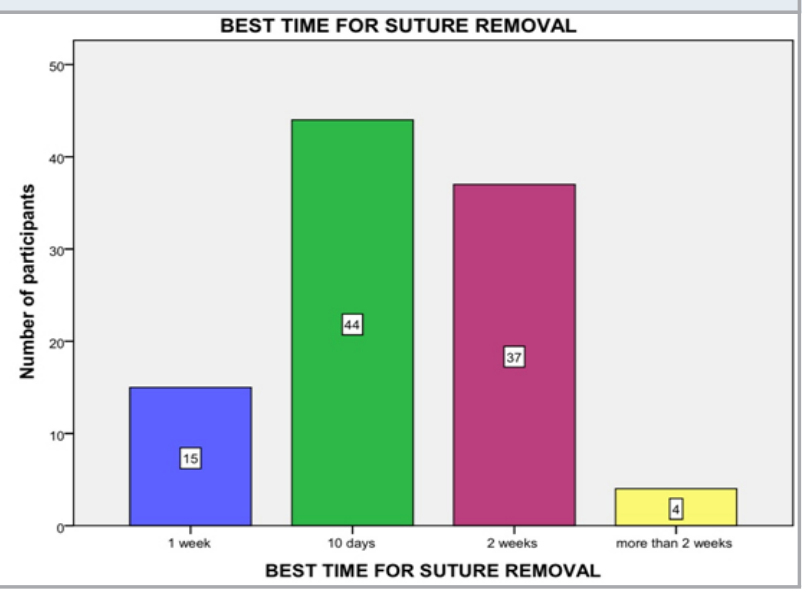

The students were asked regarding the best suture material in their opinion where $32 \%$ of students responded as natural followed by $30 \%$ as synthetic, $23 \%$ as multifilament and $15 \%$ as monofilament ( 
Figure 4). According to an article given by Teach me surgery,2020 (Suture Materials - Classification - Surgical Needles - TeachMeSurgery, no date), The ideal suture is the smallest possible to produce uniform tensile strength, securely hold the wound for the required time for healing, then be absorbed. It should be predictable, easy to handle, produce minimal reaction, and knot securely. Suture made of natural fibers (e.g. silk or catgut)are not regularly used as they provoke more tissue reaction, but used for securing surgical drains. Synthetic sutures (e.g. PDS or nylon) are more predictable than the natural sutures, particularly in their loss of tensile strength and absorption. Multifilament sutures (e.g braided silk or vicryl)are made of several filaments that are twisted together. They handle easier and hold their shape for good knot security, yet can cause infections. Monofilament sutures (e.g nylon, prolene).have a lower risk of infection but also have a poor knot security and ease of handling.

The students were also asked about the best time for suture removal where $44 \%$ of the students responded as 10 days , 37\% of them as 2 weeks, $15 \%$ as 1 week and $4 \%$ as more than 2 weeks (Figure 5). According to the study given by Alexander T. Trott MD, 2012 (Suture Removal and Wound Aftercare, 2012), the best time for suture removal is 8-14 days. After the removal of the suture, the patient should still continue to maintain the oral hygiene tips given after the surgery for 2-3 days.

When the correlation was done between the best suture material and best time for suture removal, $32 \%$ of them chose natural suture material and $27 \%$ of them think that the best time for suture removal is 10 days. The statistical Chi square test was done and the $p$ value was 0.000 which is statistically significant (Figure 6 ).

Figure 6 - Bar graph showing the correlation between the best suture material and best time for suture removal. $\mathrm{X}$ axis represents the best suture material and $Y$ axis represents the frequency of the number of dental students. Blue indicates 1 week, green indicates 10 days, violet indicates 2 weeks and yellow indicates more than 2 weeks. The graph shows that the best time for suture removal answered by the undergraduate dental students was 10 days. Chi square test was done and the association was found to be statistically significant. Pearson's value:123.791, DF:9, P value : $0.000(\mathrm{P}<0.05)$, hence significant

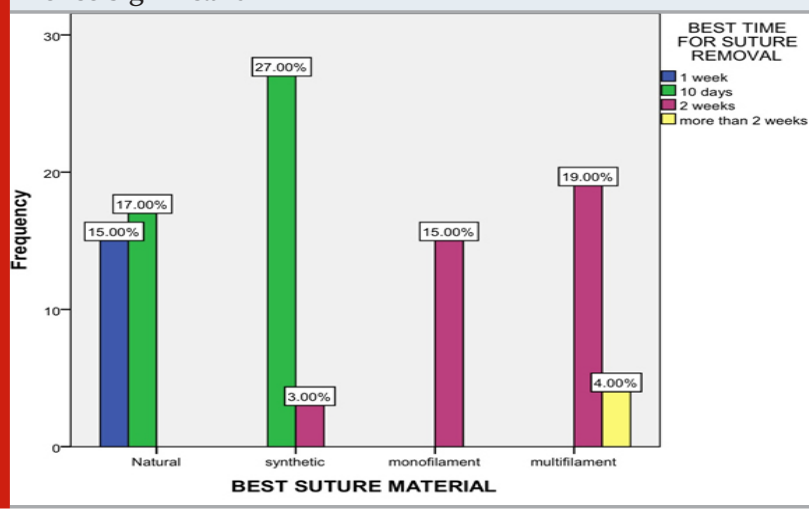

The correlation between best suturing technique and the best time for suture removal was done where $44 \%$ of the students think that 10days is the best time for suture removal and the most prevalent suturing technique was interrupted suturing technique with $74 \%$.The statistical Chi square test was done and the $\mathrm{p}$ value was 0.000 which is statistically significant( Figure 7).

Figure 7: Bar graph showing the correlation between the best suturing technique and best time for suture removal. $\mathrm{X}$ axis represents the best suturing technique and $\mathrm{Y}$ axis represents the frequency of the number of dental students. Blue indicates 1 week, green indicates 10 days, violet indicates 2 weeks and yellow indicates more than 2 weeks. The graph shows that the best time for suture removal answered by the undergraduate dental students was 10 days. Chi square test was done and the association was found to be statistically significant. Pearson's value:123.872, DF:12, $\mathrm{P}$ value : $0.000(\mathrm{P}<0.05)$, hence significant

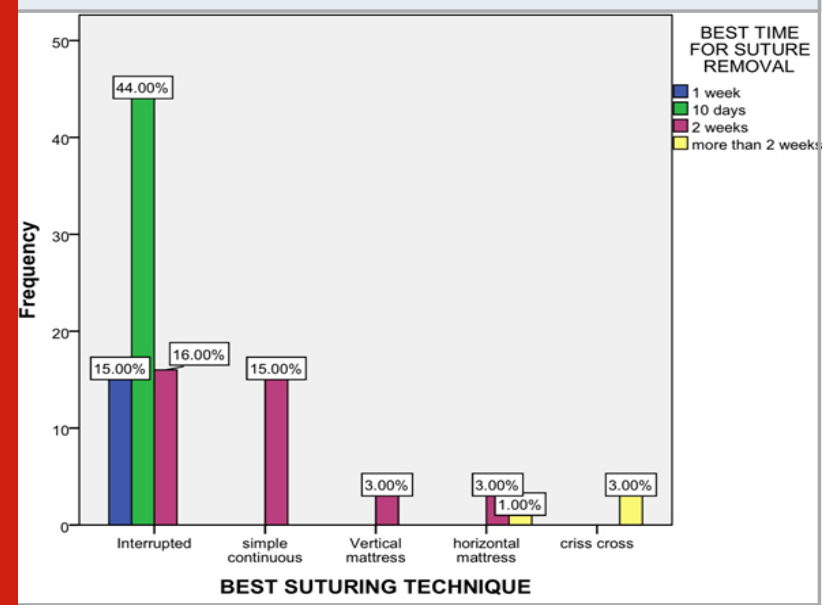

Figure 8: Bar graph showing the correlation between the best suture material and best suturing technique. $\mathrm{X}$ axis represents the best suture material and $\mathrm{Y}$ axis represents the frequency of the number of dental students. Blue indicates Interrupted, green indicates Simple continuous, white indicates vertical mattress, violet indicates horizontal mattress and red indicates criss cross. The graph shows the best suturing technique answered by the undergraduate dental students which was Interrupted suturing technique. Chi square test was done and the association was found to be statistically significant. Pearson's value:91.930, DF:12, P value : $0.000(\mathrm{P}<0.05)$, hence significant.

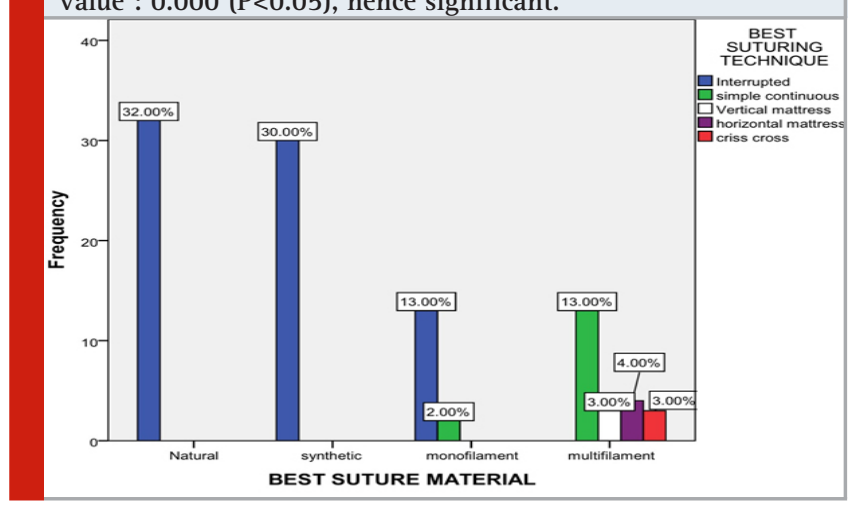


Also, the correlation between the best suture material and best suturing technique was done, where the Interrupted suturing technique showed the highest prevalence with 75\% and natural suture material with 32\%.The statistical Chi square test was done and the $\mathrm{p}$ value was 0.000 which is statistically significant (Figure 8).

\section{CONCLUSION}

Within the limits of the study, the dental students were aware of the various suturing techniques used in minor oral surgeries. More awareness should be created among the students on the suturing materials, suturing techniques and suture removal as it helps in their dental practice.Similar studies on large populations should be done in order to get the relevant results. This study will act as a guide to understand the awareness of various suturing techniques used in minor oral surgeries among dental students.

\section{ACKNOWLEDGEMENTS}

The authors would like to acknowledge the Chancellor, Director of academics, the Principal, Associate Dean of Research, the Vice Chancellor of Saveetha University, HOD and their Professors, Readers, Lecturers and their fellow post graduates, Department of Oral and Maxillofacial Surgery of Saveetha Dental College.

Conflict of Interest: The authors would like to declare that there is no conflict of interest.

\section{REFERENCES}

Abdul Wahab, P. U. et al. (2017) 'Risk Factors for Postoperative Infection Following Single Piece Osteotomy', Journal of maxillofacial and oral surgery, 16(3), pp. 328-332.

Abhinav, R. P. et al. (2019) 'The Patterns and Etiology of Maxillofacial Trauma in South India', Annals of maxillofacial surgery, 9(1), pp. 114-117.

Andrade, M. G. S., Weissman, R. and Reis, S. R. A. (2006) 'Tissue reaction and surface morphology of absorbable sutures after in vivo exposure', Journal of materials science. Materials in medicine, 17(10), pp. 949-961.

Atlas of cosmetic and reconstructive periodontal surgery' (1995) Journal of Oral and Maxillofacial Surgery, p. 976. doi: 10.1016/0278-2391(95)90314-3. Dragovic, M. et al. (2020) 'Comparison of four different suture materials in respect to oral wound healing, microbial colonization, tissue reaction and clinical features-randomized clinical study', Clinical Oral Investigations, pp. 1527-1541. doi: 10.1007/s00784019-03034-4.

Eapen, B. V., Baig, M. F. and Avinash, S. (2017) 'An Assessment of the Incidence of Prolonged Postoperative Bleeding After Dental Extraction Among Patients on Uninterrupted Low Dose Aspirin Therapy and to
Evaluate the Need to Stop Such Medication Prior to Dental Extractions', Journal of maxillofacial and oral surgery, 16(1), pp. 48-52.

Eliason, J. A. and McCulley, J. P. (1990) 'A Comparison

Between Interrupted and Continuous Suturing Techniques in Keratoplasty', Cornea, p. 10???16. doi: 10.1097/00003226-199001000-00003.

Gomez, L. (2007) 'Wound Closure Material', Manual of Operating Room Techniques, pp. 133-133. doi: 10.5005/ jp/books/11974_13.

Griffin, T. J., Hur, Y. and Bu, J. (2011) 'Basic Suture Techniques for Oral Mucosa', Clinical Advances in Periodontics, pp. 221-232. doi: 10.1902/ cap.2011.110053.

Howe, G. L. and Zamet, J. S. (1971) Minor Oral Surgery. Butterworth-Heinemann.

Jain, M. and Nazar, N. (2018) 'Comparative Evaluation of the Efficacy of Intraligamentary and Supraperiosteal Injections in the Extraction of Maxillary Teeth: A Randomized Controlled Clinical Trial', The journal of contemporary dental practice, 19(9), pp. 1117-1121.

J, P. C. et al. (2018) 'Prevalence and measurement of anterior loop of the mandibular canal using CBCT: A cross sectional study', Clinical implant dentistry and related research, 20(4), pp. 531-534.

Kim, J.-S. et al. (2011) 'Tissue reactions to suture materials in the oral mucosa of beagle dogs', Journal of Periodontal \& Implant Science, p. 185. doi: 10.5051/ jpis.2011.41.4.185.

Koshak, H. H. (2017) 'Dental Suturing Materials and Techniques', Global Journal of Otolaryngology. doi: 10.19080/gjo.2017.12.555833.

Malik, N. A. (2016) Textbook of Oral and Maxillofacial Surgery. JP Medical Ltd.

Marimuthu, M. et al. (2018) 'Canonical Wnt pathway gene expression and their clinical correlation in oral squamous cell carcinoma', Indian journal of dental research: official publication of Indian Society for Dental Research, 29(3), pp. 291-297.

Marsh, G. (2001) 'Tissue regeneration the material enablers', Materials Today, pp. 38-41. doi: 10.1016/ s1369-7021(01)80037-7.

Patil, S. B. et al. (2017) 'Comparison of Extended Nasolabial Flap Versus Buccal Fat Pad Graft in the Surgical Management of Oral Submucous Fibrosis: A Prospective Pilot Study', Journal of maxillofacial and oral surgery, 16(3), pp. 312-321.

Postlethwait, R. W., Willigan, D. A. and Ulin, A. W. (1975) 'Human tissue reaction to sutures', Plastic and Reconstructive Surgery, p. 233. doi: 10.1097/00006534197508000-00082.

Ramadorai, A., Ravi, P. and Narayanan, V. (2019) 'Rhinocerebral Mucormycosis: A Prospective Analysis 
of an Effective Treatment Protocol', Annals of maxillofacial surgery, 9(1), pp. 192-196.

Senthil Kumar, M. S. et al. (2019) 'Inflammatory pseudotumour of the maxillary sinus: clinicopathological report', Oral Surgery, 12(3), pp. 255-259.

Siervo, S. (2008) Suturing Techniques in Oral Surgery. Quintessence Publishing Company.

Suture Materials - Classification - Surgical Needles TeachMeSurgery (no date) TeachMeSurgery. Available at: https://teachmesurgery.com/skills/theatre-basics/ suture-materials/ (Accessed: 2 July 2020).

Suture Removal and Wound Aftercare (2012). W.B. Saunders, pp. 288-293.

Sweta, V. R., Abhinav, R. P. and Ramesh, A. (2019) 'Role of Virtual Reality in Pain Perception of Patients Following the Administration of Local Anesthesia', Annals of maxillofacial surgery, 9(1), pp. 110-113.
Taylor, B. and Bayat, A. (2003) 'Basic plastic surgery techniques and principles: Choosing the right suture material', BMJ, p. 0305140. doi: 10.1136/ sbmj.0305140.

Trimbos, J. B., Van Rijssel, E. J. C. and Klopper, P. J. (1986) 'Performance of sliding knots in monofilament and multifilament suture material', Obstetrics \& Gynecology, pp. 425-430. doi: 10.1097/00006250198609000-00029.

Wahab, P. U. A. et al. (2018) 'Scalpel Versus Diathermy in Wound Healing After Mucosal Incisions: A SplitMouth Study', Journal of oral and maxillofacial surgery: official journal of the American Association of Oral and Maxillofacial Surgeons, 76(6), pp. 1160-1164.

Wilson, D. (2006) 'Wound Closure', Manual of Equine Field Surgery, pp. 11-23. doi: 10.1016/b978-1-41600270-3.50006-3. 